\title{
N-terminal amino acids of bovine alpha interferons are relevant for the neutralization of their antiviral activity
}

\section{J.B. Barreto Filho ${ }^{1}$, \\ P.R.S. Eiras ${ }^{1}$ and \\ R.R. Golgher ${ }^{2}$}

\author{
'Departamento de Medicina Veterinária, Universidade Federal de Lavras, \\ Lavras, M G, Brasil \\ ${ }^{2}$ Centro de Pesquisas René Rachou, FIO CRUZ, Belo Horizonte, M G, Brasil
}

\begin{abstract}
Correspondence
R.R. Golgher

Rua Expedicionário Alício, 166

30315-220 Belo Horizonte, MG

Brasil

Fax: +55-31-281-2224

E-mail: rgolgher@ terra.com.br

Research supported by Fundação O swaldo Cruz, FAPEMIG and CNPq J.B. Barreto Filho and P.R.S. Eiras were recipients of CNPq fellowships. R.R. Golgher was a research fellow of the CN Pq-FIOCRUZ cooperation program.
\end{abstract}

Received March 2, 2000 Accepted February 16, 2001

\section{Abstract}

The structure-function relationship of interferons (IFNs) has been studied by epitope mapping. Epitopes of bovine IFNs, however, are practically unknown, despite their importance in virus infections and in the maternal recognition of pregnancy. It has been shown that recombinant bovine ( $\mathrm{rBo}$ )IFN- $\alpha \mathrm{C}$ and $\mathrm{rBoIFN}-\alpha 1$ differ only in 12 amino acids and that the F12 monoclonal antibody (mAb) binds to a linear sequence of residues 10 to 34 . We show here that the antiviral activities of these two IFNs were neutralized by the F12 mAb to different extents using two tests. In residual activity tests the antiviral activity dropped by more than $99 \%$ with $\mathrm{rBoIFN}-\alpha \mathrm{C}$ and by $84 \%$ with rBoIFN- $\alpha 1$. In checkerboard antibody titrations, the F12 mAb titer was 12,000 with $\mathrm{rBoIFN}-\alpha \mathrm{C}$ and only 600 with $\mathrm{rBoIFN}-\alpha 1$. Since these IFNs differ in their amino acid sequence at positions 11, 16 and 19 of the amino terminus, only these amino acids could account for the different neutralization titers, and they should participate in antibody binding. According to the three-dimensional structure described for human and murine IFNs, these amino acids are located in the $\alpha$ helix A; amino acids 16 and 19 of the bovine IFNs would be expected to be exposed and could bind to the antibody directly. The amino acid at position 11 forms a hydrogen bond in human IFNs- $\alpha$ and it is possible that, in bovine IFNs- $\alpha$, the F12 mAb, binding near position 11, would disturb this hydrogen bond, resulting in the difference in the extent of neutralization observed.

Interferons (IFNs) are a family of cytokines that induce several activities in cells, including an antiviral state and inhibition of cell growth. In the immune system, IFNs activate natural killer cells, macrophages and cytotoxic T cells. They induce MHC antigen expression and modulate the synthesis of immunoglobulin by B cells. The cells of most vertebrates produce IFNs which are divided into type I and type II IFNs. Type I IFNs are classified as IFN- $\alpha$, IFN- $\beta$, IFN- $\omega$ and IFN- $\tau$ subtypes, while type II IFN is

\section{Key words}

- Bovine alpha interferon

- Neutralization

- Amino acid

- Epitope represented solely by IFN- $\gamma$. All the animal species investigated have large IFN- $\alpha$ subfamilies but only one gene for IFN- $\beta$, with the exception of ungulates, which have at least five genes (1).

Several approaches have been used to relate structure to function in IFNs and most investigations have been done using human and murine IFNs. To this end, truncated IFNs from either end of the protein, hybrid molecules derived from the same or different animal species or molecules with changes in 
specific amino acids were used (2). Another approach used to explore the structure-function relationship is the use of a panel of monoclonal antibodies (mAb) obtained with a single IFN as the source of antigen because it is possible to map the antigenic sites of this and related IFNs by neutralizing their biological activities. This has been done with recombinant IFNs with the natural sequence, with hybrid or truncated molecules and with IFN peptides (3-5). A better understanding of the structure-function relationship was reached with the recent knowledge on the three-dimensional structure of human and murine type I IFNs (6-8). Human IFN- $\alpha 2 a$, $-\alpha 2 b$ and $-\beta$ have five $\alpha$ helices denominated $\mathrm{A}, \mathrm{B}, \mathrm{C}, \mathrm{D}$ and $\mathrm{E}$, connected with loops $\mathrm{AB}$, $\mathrm{BC}, \mathrm{CD}$ and $\mathrm{DE}$; the murine IFN $-\beta$ has a short sixth helix located within the CD loop. Furthermore, these investigations demonstrated that human $\alpha$ and $\beta$ and murine $\beta$ IFN display a considerable structural similarity which allows comparisons between these proteins and IFNs from other animal species, including cattle.

In cattle, the IFN- $\alpha$ subfamily contains more than 15 genes and IFN- $\beta,-\omega$ and $-\tau$ also have multiple genes (9). The several IFNs- $\alpha$ cloned share an amino acid sequence identity ranging from 91 to $99 \%$ (10-12). The production of IFNs was shown to be an important response in natural viral infections of cattle (13) and the application of IFN therapy for experimental diseases has been studied (14). In ruminants, IFN- $\tau$ is secreted by the embryo and is essential for the maternal recognition of pregnancy (9); it has been used in attempts to reduce embryo mortality (15).

Despite the importance of the bovine IFNs, very few studies on the structure-function relationship of these proteins are available. The amino acid sequence from position 1 to 44 is not essential for the activity of recombinant bovine ( $\mathrm{rBo}$ )IFN- $\alpha \mathrm{C}$ since this sequence could be changed for the human$\alpha \mathrm{J} 1$ sequence without loss of the antiviral or 2'5'oligoadenylate synthetase-inducing activities in Martin Darby bovine kidney (MDBK) cells (16).

In the present research, we have extended the study of the structure-function relationships of rBoIFN- $\alpha$. We have taken advantage of the fact that the amino acid sequences of the mature molecules of rBoIFN- $\alpha \mathrm{C}$ and rBoIFN- $\alpha 1$ differ at 12 positions: $6,11,16$, $19,75,76,84,87,98,105,107$ and 161 $(10,11)$ and that a mAb, F12, neutralizes rBoIFN- $\alpha \mathrm{C}$ by binding to a linear epitope located between amino acids 10 and 34 (4). We have compared the neutralizing activity of mAb F12 on these IFNs and found a significant difference despite the fact that there are only three amino acid differences in this entire region.

$r B o I F N-\alpha 1$ (11) was kindly donated by Dr. R.M. Roberts (Columbia, MO, USA) and $\mathrm{rBoIFN}-\alpha \mathrm{C}$ by Dr. A. Shafferman (Ness Ziona, Israel). rBoIFN- $\alpha 1$ and $\mathrm{rBoIFN}-\alpha \mathrm{C}$ had specific activities of $1.5 \times 10^{8}$ units and $2 \times 10^{8}$ units/mg protein, respectively. The neutralizing F12 mAb was obtained using rBoIFN $-\alpha \mathrm{C}$ as the antigen and was a generous gift from Dr. A. Shafferman. The $\mathrm{mAb}$ has an affinity constant of $10^{8} \mathrm{x} \mathrm{M}^{-1}$ for the antigen. The ascitic fluid used contained 15 $\mathrm{mg}$ of antibody/ml (17).

The antiviral activity of the IFNs was titrated on microplates as described (16). Briefly, the IFN preparations were diluted in 2-fold steps in medium and MDBK cells were added. The cells were reincubated overnight, the medium was changed and the cells were infected with vesicular stomatitis virus (VSV) and reincubated. Virus controls without IFN and cell controls were included. At $48 \mathrm{~h}$ of infection, when the cytopathic effect was practically complete $(100 \%)$, a final reading was done. The reciprocal of the dilution of IFN reducing $50 \%$ of the cytopathic effect was taken as the IFN titer.

Two types of neutralization tests were employed: the residual activity test (18) and the checkerboard titration of the antibody 
(19). For these tests, the IFNs were first titrated and simplified checkerboard tests (see below) using 10-fold step mAb dilutions were done to determine the appropriate concentrations of the reactants. For the residual activity tests, approximately 200 IFN units were mixed with the mAb diluted $1: 1,000$ and the mixtures were held at $37^{\circ} \mathrm{C}$ for $1 \mathrm{~h}$. MDBK cells were added and the other steps were done as described above. The residual antiviral activity of the IFN$\mathrm{mAb}$ mixtures could then be read and compared to the IFN titer of the IFN control.

In the checkerboard titration (19), each IFN was diluted on microplates in 2-fold steps and one of several 2-fold step dilutions of antibody was added using two columns for each $\mathrm{mAb}$ dilution. IFN, virus and cell controls were included. Other details were as described above. The antibody titer was taken as the reciprocal of the antibody dilution that reduced the IFN activity from 8 to 1 unit. The experimental error of this test, under these conditions, had a coefficient of variation of $33 \%$ (Barreto Filho JB and Golgher RR, unpublished data).

The first experiments were residual activity tests. Experiments $(\mathrm{N}=2)$ showed that the F12 $\mathrm{mAb}$ was able to reduce the antiviral activity of its antigen, $r B o I F N-\alpha C$, to undetectable levels, the titers dropping from $480,000 \pm 0($ titer \pm SD) to less than 5,000 \pm 0 , a reduction of more than $99 \%$. In contrast, with $\mathrm{rBoIFN}-\alpha 1$, a residual activity of about $15 \%$ was observed consistently, the IFN titers dropping from $64,000 \pm 0$ to $10,000 \pm$ 3,000 .

Since it was possible that the IFN-mAb complex would dissociate upon dilution (18), a more precise test - the checkerboard test was used to substantiate the data further. Figure 1 shows the resulting titration curves. Only 4-fold dilutions were included in the graphs for clarity of presentation. While $\mathrm{mAb}$ dilutions up to $1: 4,000$ completely abolished the antiviral activity of $\mathrm{BBoIFN}-\alpha \mathrm{C}$, neutralization of $r B$ IFN- $\alpha 1$ activity required a much higher antibody concentration. From the experiments performed $(\mathrm{N}=3)$, the $\mathrm{F} 12 \mathrm{mAb}$ titer was calculated to be 20 -fold higher with rBoIFN- $\alpha \mathrm{C}(12,000)$ than with rBoIFN- $\alpha 1$ (600). When residual activity tests were done with a polyclonal antibody against rBoIFN-

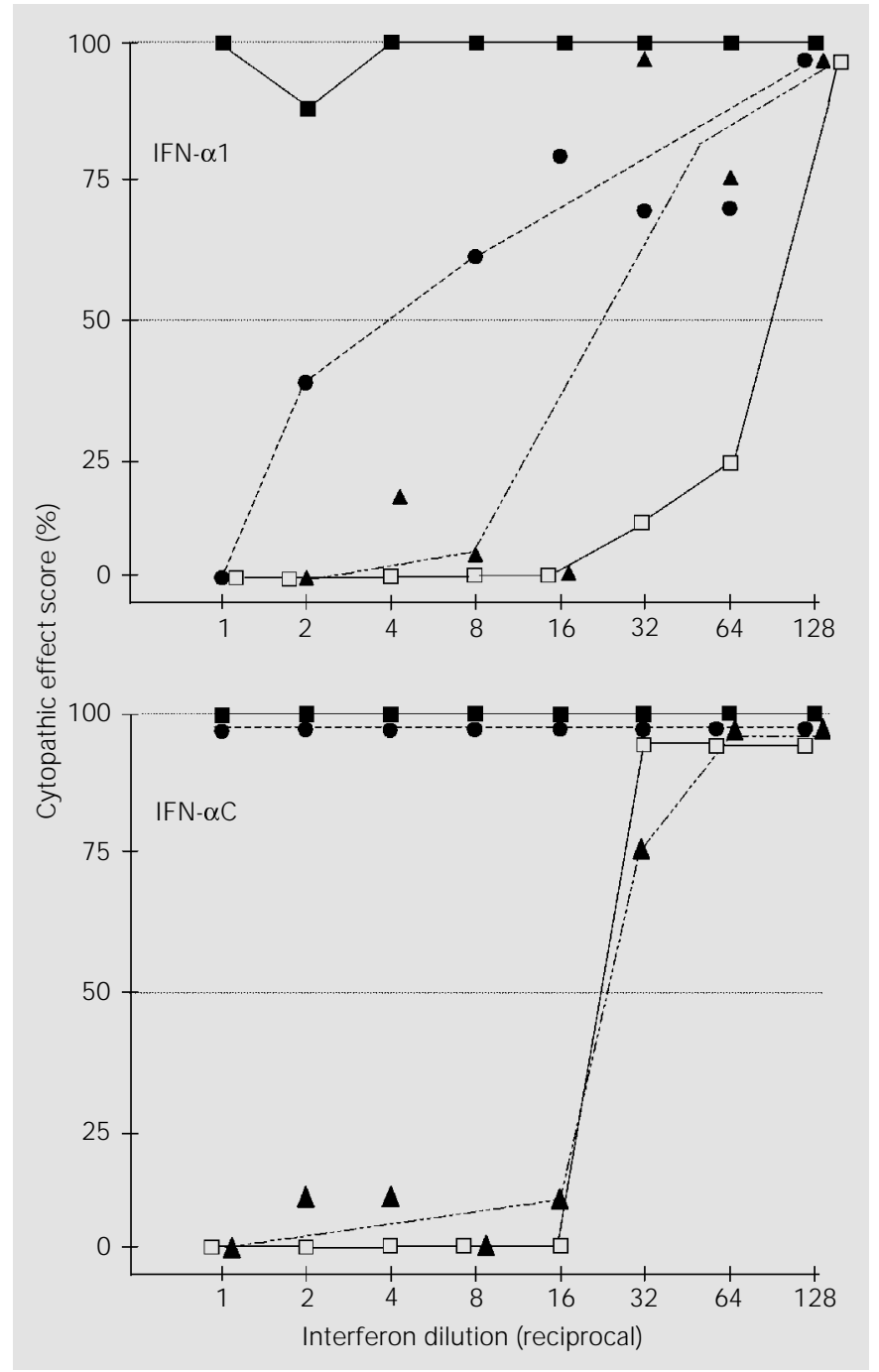

Figure 1. Neutralization of the antiviral activity of recombinant bovine interferon (IFN)- $\alpha$ by the monoclonal antibody (mAb) F12. Approximately 200 IFN units were diluted on microplate columns in 2-fold steps and mixed with one of several mAb dilutions. After 1-h incubation, Martin Darby bovine kidney (MDBK) cells were added, incubated for $24 \mathrm{~h}$ and then infected with vesicular stomatitis virus. Cytopathic effect readings were obtained $48 \mathrm{~h}$ after infection. In the experiments, mAb dilutions were performed in 2-fold steps but 4-fold steps are shown for clarity. Other details are given in Material and Methods. Upper panel, mAb dilutions 1:100 (filled squares); 1:400 (circles); 1:1,600 (triangles); no mAb, IFN control (open squares). Lower panel, 1:1,000 (filled squares); 1:4,000 (circles); 1:16,000 (triangles); no mAb, IFN control (open squares). 
$\alpha 1$, the titers dropped more than $98 \%$ for rBoIFN- $\alpha 1$ and more than $99 \%$ for rBoIFN$\alpha \mathrm{C}$ (data not shown).

These data showed that the two rBoIFN$\alpha, \alpha \mathrm{C}$ and $\alpha 1$, were neutralized to different extents by the F12 mAb. With the residual activity tests, the antiviral activity of rBoIFN$\alpha \mathrm{C}$ was reduced more than $99 \%$ when this IFN was preincubated with the F12 mAb. In contrast, with rBoIFN- $\alpha 1$, the reduction was significantly lower, to about $84 \%$. Despite the small number of experiments, the results are significant, since the coefficient of variation of the tests was $28 \%$. In the checkerboard test, the F12 mAb titer was 20-fold higher with $r B o I F N-\alpha C$ than with rBoIFN$\alpha 1$ (12,000 versus 600). Since this difference is well beyond the coefficient of variation of $33 \%$ of the method, the results can be considered to be significant. This difference cannot be explained by the mAb binding to inactive rBoIFN- $\alpha 1$ molecules, since the two IFNs had very similar specific activities as measured by the MDBK/VSV system. Moreover, at the end-points of the checkerboard tests, as illustrated in Figure 1, the concentrations of rBoIFN- $\alpha 1$ were $53 \mathrm{pg} / \mathrm{ml}$ and for the F12 mAb, $25 \mu \mathrm{g} / \mathrm{ml}$; for the rBoIFN- $\alpha \mathrm{C}$, $40 \mathrm{pg} / \mathrm{ml}$ and for the $\mathrm{F} 12 \mathrm{mAb}, 1.25 \mu \mathrm{g} / \mathrm{ml}$, showing that a saturating amount of $\mathrm{mAb}$ was available for neutralization.

rBoIFN- $\alpha \mathrm{C}$ and $\mathrm{rBoIFN}-\alpha 1$ differ in their mature protein sequence by only 12 amino acids, located at positions $6,11,16,19,75$, $76,84,87,98,105,107$, and $161(10,11)$. As the F12 mAb binds to the linear amino acid sequence $10-34$ of the rBoIFN- $\alpha \mathrm{C}$ (4), we concluded that the amino acids at positions 11,16 and 19 of the amino end should be responsible for the difference in antibody neutralization activity (Figure 1).

The recent data on the three-dimensional structure of type I IFNs can help understand further the role of these amino acids in the neutralization of bovine IFNs- $\alpha$. Human IFN$\alpha 2 b$ has five $\alpha$ helices connected with loops. The A helix consists of amino acids 9 to 21 ; helix B, of 51 to 74 ; helix C, of 77 to 100 ; helix D, of 112 to 131 , and helix E, of 136 to 159 (20). This molecular configuration is practically identical to human IFN- $\alpha 2 a$ and very similar to human and murine IFNs- $\beta$, including human IFN- $\alpha$ consensus 1 and murine IFN-B (6-8). The amino acid sequence identity between human IFN- $\alpha$ consensus 1 and murine IFN- $\beta$ is $26 \%$ (20) and between bovine IFN- $\alpha$ and human IFN- $\alpha$ is much higher - $62 \%(11,12)$. Therefore, given the very high structural similarity of $\alpha$ and $\beta$ IFNs, which has been described, it is reasonable to assume that bovine IFNs- $\alpha$ will have the same structural pattern and that amino acids 10 to 34 of $r B o I F N-\alpha C$ and $-\alpha 1$ should be located in helix A.

In this helix, the amino acids at positions 16 and 19 of several bovine type I IFNs are exposed (6) and therefore they could bind directly to a mAb. Since the amino acids at these positions of the two IFNs used in this investigation are different (amino acid 16 for the $\operatorname{rBoIFN}-\alpha 1$ is a threonine and for the $\mathrm{rBoIFN}-\alpha \mathrm{C}$ is a methionine; amino acid 19 is an arginine for the $\mathrm{rBoIFN}-\alpha 1$ and a glycine for the rBoIFN- $\alpha \mathrm{C}$ ), these changes could lead to different degrees of binding to the $\mathrm{mAb}$ resulting in the neutralization titers obtained. However, our results could also be explained by a single amino acid difference at position 11. In human IFN- $\alpha 2 b$, this position is occupied by a serine buried in the center of the hydrophobic core and forming a hydrogen bond with threonine 155; in human IFN- $\alpha$ consensus 1 , it is occupied by an asparagine that may form a hydrogen bond with both glutamine 91 and threonine 155 (20). Position 11 is an asparagine in the rBoIFN- $\alpha \mathrm{C}$ and a lysine in the $\mathrm{rBoIFN}-\alpha 1$; for both IFNs, position 91 is a glutamine and position 155 is a threonine. It is possible that these amino acids at position 11 in bovine IFNs also form a hydrogen bond. The binding of an antibody to the exposed surface of bovine IFN- $\alpha$ near this position may cause indirect changes in the conformation of the 
region, affecting the hydrogen bond and hence explaining the differences in $\mathrm{mAb}$ neutralization.

Models of IFN binding to its receptor implicate the A helix in the binding of several type I IFNs (6) or human IFN- $\alpha 2 b$ and $-\alpha 2 \mathrm{a}(7,8)$. Thus, it is possible that this helix of bovine IFNs- $\alpha$ also takes part in the IFNcell receptor binding and our data support this view. However, we cannot exclude at this point the possibility that the differences in neutralization observed are a result of the antibody causing steric hindrance to IFN binding. Only when the three-dimensional structure of the IFN- $\alpha$ receptor complex is known can this question be answered.

\section{Acknowledgments}

The authors thank Dr. A. Shafferman for supplying rBoIFN- $\alpha \mathrm{C}$ and the monoclonal antibody F12, Dr. R.M. Roberts for supplying rBoIFN- $\alpha 1$ and the polyclonal antibody against this IFN, and Dr. D.B. Golgher, Dr. K.J. Gollob, Dr. R.M. Roberts and Dr. A.D. Ealy for reviewing the manuscript.

\section{References}

1. VilcekJ \& Sen GC (1996). Interferons and other cytokines. In: Fields BN, Knipe DM, Howley PM, Chanock RM, Melnick JL, Monath TP, Roizman B \& Straus SE (Editors), Fundamental Virology. 3rd edn. Lippincott-Raven Publishers, Philadelphia.

2. Horisberger MA \& Di Marco S (1995). Interferon-alpha hybrids. Pharmacology and Therapeutics, 66: 507-534.

3. Lydon NB, Favre C, Bove S, Neyret O, Benureau S, Levine AM, Seelig GF, Nagabhushan TL \& Trotta PP (1985). Immunochemical mapping of $\alpha-2$ interferon. Biochemistry, 24: 4131-4141.

4. Velan B, Cohen S, Elhanati E, Brodt P, Grosfeld H \& Shafferman A (1990). Linear peptides overlapping the cell recognition domain of bovine interferon $\alpha$ are insufficient for induction of antiviral state. In: White MD, Reuveny $S \&$ Shafferman A (Editors), Biologicals from Recombinant Microorganisms and Animal Cells. Production and Recovery. Proceedings of the 34th Oholo Conference, Eilat, Israel. Balaban Publishers, Weinheim.

5. Redlich PN \& Grossberg SE (1989). Analysis of antigenic domains on natural and recombinant human IFN- $ß$ by the inhibition of biologic activities with monoclonal antibodies. J ournal of Immunology, 143: 1887-1893.

6. Senda T, Saitoh S \& Mitsui Y (1995). Refined crystal structure of recombinant murine interferon- $\beta$ at $2.15 \AA$ resolution. J ournal of Molecular Biology, 253: 187207.

7. Radhakrishnan R, Walter LJ, Hruza A, Reichert P, Trotta PP, Nagabhushan TL \&
Walter MR (1996). Zinc mediated dimer of human interferon $\alpha 2 \mathrm{~b}$ revealed by $\mathrm{X}$ ray crystallography. Structure, 4: 14531463.

8. Klaus W, Gsell B, Labhardt AM, Wipf B \& Senn $H$ (1997). The three-dimensional high resolution structure of human interferon $\alpha$-2a determined by heteronuclear NMR spectroscopy in solution. J ournal of Molecular Biology, 274: 661-675.

9. Roberts RM, Liu L \& Alexenko A (1997). New and atypical families of type I interferons in mammals: comparative functions, structures and evolutionary relationships. Progress in Nucleic Acid Research and Molecular Biology, 56: 287-325.

10. Velan B, Cohen C, Grosfeld H, Leitner M $\&$ Shafferman A (1985). Bovine interferon $\alpha$ genes. J ournal of Biological Chemistry, 260: 5498-5504.

11. Capon DJ, Shepard HM \& Goeddel DV (1985). Two distinct families of human and bovine interferon- $\alpha$ genes are coordinately expressed and encode functional polypeptides. Molecular and Cellular Biology, 5: 768-779.

12. Chaplin PJ , Entrican G, Gelder KI \& Collins RA (1996). Cloning and biologic activities of a bovine interferon- $\alpha$ isolated from the epithelium of a rotavirus-infected calf. J ournal of Interferon Research, 16: 25-30.

13. Stewart II WE (1981). The Interferon System. 2nd edn. Springer Verlag, New York.

14. Babiuk LA, Ohmann HB, Gifford G, Czamiecki CW, Scialli VT \& Hamilton EB (1985). Effect of bovine $\alpha 1$ interferon on bovine herpesvirus type 1-induced respiratory disease. J ournal of General Virol- ogy, 66: 2383-2394.

15. Bleach ECL, Peiris ID, Grewal TS, Sheperd DAL \& Savva D (1998). Effect of administration of a novel recombinant bovine interferon on length of oestrus cycle in cattle. Research in Veterinary Science, 64: 73-77.

16. Shafferman A, Velan B, Cohen S, Leitner $M \&$ Grosfeld H (1987). Specific residues within an amino-terminal domain of 35 residues of interferon $\alpha$ are responsible for recognition of the human interferon $\alpha$ cell receptor and for triggering biological effects. J ournal of Biological Chemistry, 262: 6227-6237.

17. Kobiler D, Grosfeld H, Leitner M, M onzain $\mathrm{R}$, Frist C, Seri $T$, Cohen S, Velan B, Shafferman A \& Gozes Y (1989). Production of monoclonal antibodies toward bovine interferons- $\alpha$ suitable for immunopurification. J ournal of Interferon Research, 9: 189-193.

18. Kawade $Y$ (1986). Quantitation of neutralization of interferon by antibody. In: Pestka S (Editor), Interferons. Part C. Methods in Enzymology, 119: 558-573.

19. Dalton B \& Paucker K (1981). Preparation and adsorption of antiserum against human leukocyte interferon. In: Pestka S (Editor), Interferons. Part B. Methods in Enzymology, 79: 561-567.

20. Walter MR (1997). Three-dimensional models of interferon- $\alpha$ subtypes IFNcon 1, IFN- $-\alpha 8$ and IFN- $\alpha 1$ derived from the crystal structure of IFN- $\alpha 2$ b. Seminars in Oncology, 24 (Suppl 9): 52-62. 